\title{
Delivering Healthcare to Rural Ghana: telmedx and Mahiri Mobile Serve Patients in Remote Areas
}

Clint Carney, JD

The quality of healthcare varies greatly throughout Ghana. Urban centers are well served, with hospitals, clinics, and pharmacies. In comparison, rural areas often lack modern healthcare. Patients in these areas either rely on traditional African medicine or travel great distances for western healthcare.

In 2010, the Government of Ghana launched the national e-health strategy. The key components included streamlining the regulatory framework for health data and information management, building sector capacity for wider application of eHealth solutions in the health sector, increasing access and bridging equity gap in the health sector through the use of information and communication technology, and development of a paperless records and reporting system.

\section{Connecting Tamale and Nsawam, Ghana}

Today, doctors in Tamale in the north of Ghana and in Nsawam, in the south are delivering improved healthcare to remote areas of the country without traveling to see patients in person (Figure 1). Mahiri Mobile Services of Accra outfitted nurses in rural villages with wireless tablets that deliver high quality, live medical-grade video from telmedx to doctors in Tamale and Nsawam for medical advice (Figure 2). The system makes it possible to treat medical conditions from skin disorders and infections to neurological conditions to maternity and pre-natal care that would otherwise not be managed by physicians. Ghana has 1 physician per 10,000 people compared to 24.5 per 10,000 in the United States. 
Examples of the types of medical conditions treated with the Mahiri-telmedx platform are shown in the photos (Figure 3). "We are now addressing cases that would not have come to the hospital due to a lack of money for travel or a lack of knowledge about access to our hospital," states Dr. Sophie Winful at Nsawam District Hospital, in eastern Ghana.

Patients are seen at home, in remote clinics, in schools, or during community gatherings by traveling nurses trained to use the technology, which was developed by telmedx, San Diego, California. It allows a doctor using a web browser to examine patients over the high-resolution cameras of mobile phones and tablets for real-time consultations. Doctors can also take high-resolution photos of patient conditions from a web browser by remotely controlling the backup cameras on wireless phones and tablets. The live video and still photos appear side-by-side on a computer screen, and doctors easily save the photos into the medical records.

Nurses responsible for visits to homes, schools, mobile clinics, community gatherings, child welfare clinics, and emergency delivery are enthusiastic about the new mobile video platform. "This has boosted home visits and school health service visits, and we now know more about ailments and skin disorders that occur out in the rural villages," says one field nurse with Nsawam District Hospital.

\section{Mobile Telemedicine Solutions}

The telmedx mobile video platform also allows groups of doctors and specialists to watch the same live video. Doctors capture photos for closer analysis and seamless consultations. "This is a cheaper alternative for addressing people in remote areas. Specialists would otherwise need to travel long distances to those areas, which can even require using helicopters or having to tar the roads leading to a village," says Dr. Adam Abass, Consultant Neurosurgeon at Tamale Teaching Hospital in northern Ghana. 
The mobile telemedicine program has been active in Ghana for several months, and has received praise and recognition by doctors for the quality of the video and photos. "The video resolution and image quality delivered by the telmedx platform are unparalleled," states Diana Dwamena, founder of Mahiri Mobile. "At first the doctors and nurses were sceptical, but now they realize that this technology helps them deliver the quality of care they desire. This is the way forward."

Mahiri Mobile also has a system that enables nurses to gather patient information and assign patient records using the telemedicine platform. In less than two months, more than 700 patients were treated with the Mahiri-telmedx system. Otherwise, these patients would not have had the benefit of real-time direct doctor involvement.

In addition to providing access to doctors and nurses, the Mahiri system engages patients as full participants in their healthcare. They often want to see themselves on the mobile tablets and show the doctors other possible medical conditions. "For the community, patients can be comforted by the knowledge that the doctor is seeing them live, and by knowing that they will be seen by a specialist. They are excited to know that someone in the "big hospital" is coming to see them, and that has a positive psychological effect," stated Dr. Abass.

Tags: Africa, Ghana, healthcare, health care, Mahiri Mobile, patients, platform, remote, rural, Telmedx

Clint Carney, JD, is Vice President, Business Development \& External Affairs, telmedx \& telvuex. He can be reached at ccarney@telmedx.com. +1.619.917.6003. www.telmedx.com.

Editor's note: Telehealth and Medicine Today is most interested in publishing original articles and can provide expedited review for manuscripts that cover, for example, how 
companies in the telehealth space advised clients on designing an effective telemedicine program, the elements of a typical program, an example of scaling programs, and estimated costs/savings to clients and users of the service.

For more information about this program in Ghana, contact:

John Broni

Project Manager, Telemedicine

Mahiri Mobile Services, Ltd.

john.broni@mahirimobile.com

Ghana: +233 (0) 262243997

www.mahirimobile.com

\section{About Mahiri Mobile Services}

Mahiri Mobile of Accra, Ghana is a wireless communications provider that delivers application solutions for the workforce on the move. Mahiri provides relevant, agile and cost effective solutions to meet customer needs. More information on the company is available at www.mahirimobile.com

\section{About Mahiri Mobile Services}

Mahiri Mobile of Accra, Ghana is a wireless communications provider that delivers application solutions for the workforce on the move. Mahiri provides relevant, agile and cost effective solutions to meet customer needs. More information on the company is available at www.mahirimobile.com.

\section{About telmedx}

With headquarters at the Johnson \& Johnson Innovation JLabs in San Diego, CA, telmedx provides live high quality live medical-grade vide ${ }^{\mathrm{TM}}$ from wireless phones and tablets to any web browser. The company's HIPAA/HITECH and EU-compliant telemedicine platform helps reduce costs, increase efficiency, manage risk and create 
\#11115 001. Carney. Delivering. https://doi.org/10.30953/tmt.v2.67 Page 5 of 6 Department: New Products and Devices new revenue opportunities for healthcare providers. More information is available at www.telmedx.com.

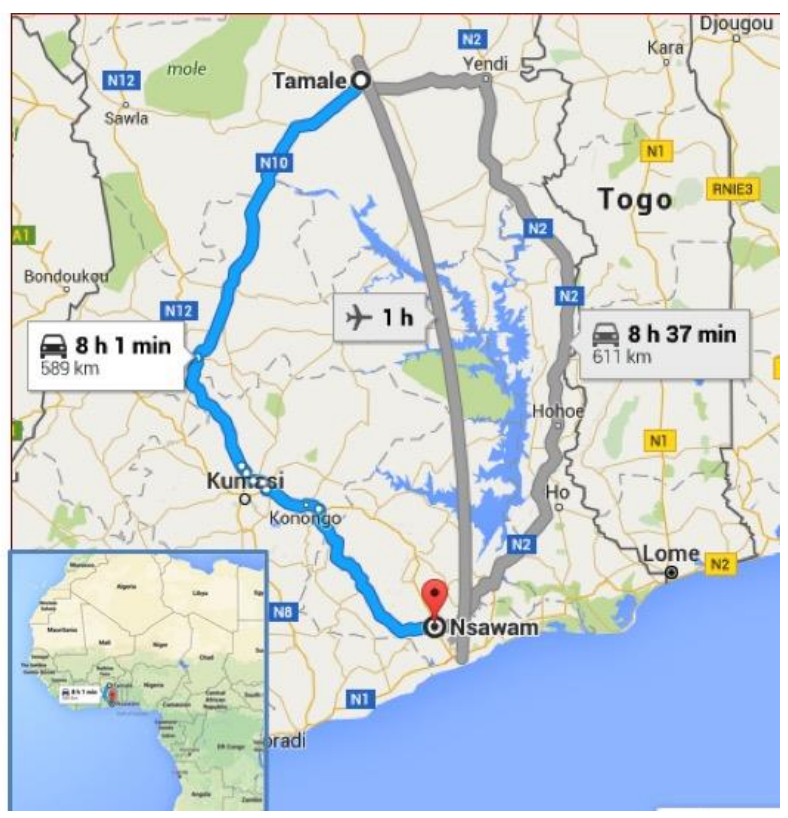

Figure 1. Map shows the west coast of Africa (insert) and the 8-hour driving distance from Tamale, Ghana in the north to Nsawam, Ghana in the south. 
\#11115 001. Carney. Delivering. https://doi.org/10.30953/tmt.v2.67 Page 6 of 6 Department: New Products and Devices

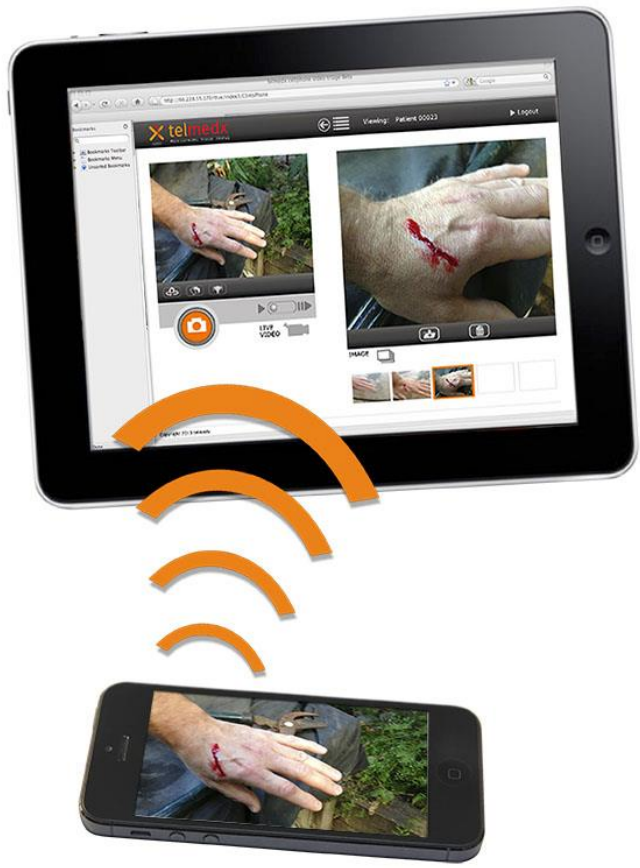

Figure 2. The telmedx mobile video platform allows doctors to watch live steaming video.

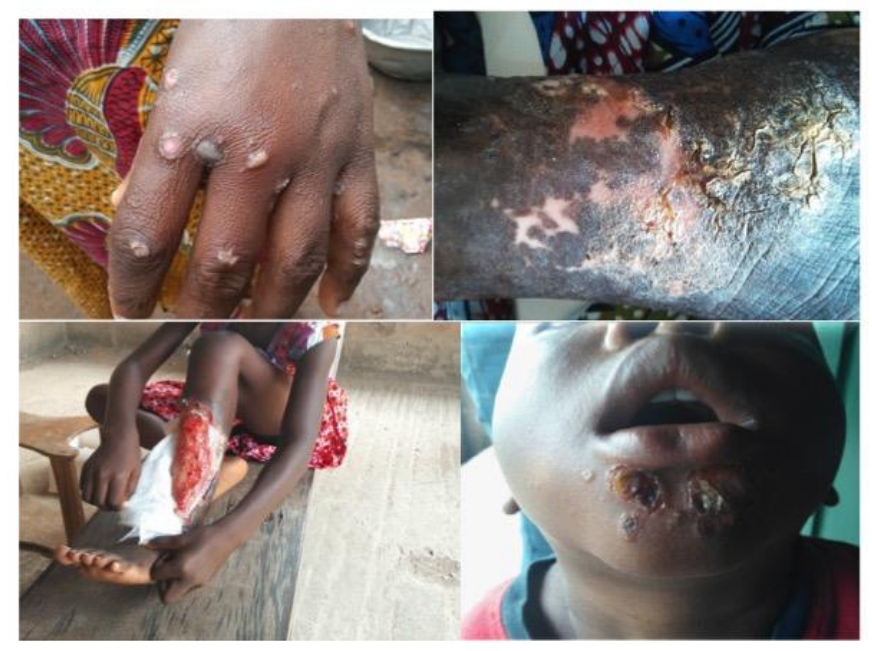

Figure 3. Traveling nurses in Ghana use the telmedx platform to show doctors serious skin conditions that may otherwise go untreated. Shown here are warts from milking goats without protection, a type of flesh-eating bacteria, and two other dermatology conditions that went untreated for many weeks. 